\title{
Study on Coupling Degree and Optimal Path between Land Water Resources and Economic Development in Poyang Lake Ecological Economical Zone
}

\author{
Tian-gui Lv and Ci-fang $\mathrm{Wu}$
}

\begin{abstract}
The coordination between resources and economy is a challenge for Poyang Lake Ecological Economic Zone, which is a new economic development zone in China, with the rapid development in the past few years, the contradiction is more intense than ever before. In this paper, the coupling degree between the carrying capacity of land water resources and economical development were assessed to demonstrate how optimal coupling path can be selected. Methods of information entropy were employed to determine the guideline system of coupling degree and to quantify them. The results indicated that: 1)The coupling degree was difference, the level of urban regions level was much higher than the counties region; 2)The carrying capacity of land water and economic development lacked the synchrony, most of the urban were belongs to the low harmony style, and the countries were belongs to the phase lag in economy; 3)The spatial distribution of the coupling degree took Poyang lake as the core from higher to lower in the form of the concentric circles. It obvious that the strategy of adaptive management and ecological barrier construction should be selected in environment damage areas, while the strategy of urbanization and industrial layout optimization should be selected in the Lag of economy of region.
\end{abstract}

Index Terms-Carrying capacity of land and water resources, coupling degree, economical development, Poyang Lake Ecological Economical Zone.

\section{INTRODUCTION}

Resolving the conflicts between economic development and resource endowment is a challenging task that we often have to face in the long history of human development [1]. Land and water resources as the most basic natural resources for social economic development, which have their unique ecological features, and the coupling degree of water and soil resources is vital to the regional social and economic sustainable development [2].

However, with the rapid development of China's industrialization and urbanization, the land and water resources are a substantial increase in demand for urban construction, and also coupling with the water shortage owing to the regional engineering and the seasonal factors. All these factors further highlight the contradiction between the carrying capacity of land and water resources and economic development in China.

The mentioned above contradiction clearly highlight a critical question to many regions or ecological economic

Manuscript received March 12, 2013; revised May 14, 2013.

All the authors are with the department of land resources management, College of Public Administration, Zhejiang University, Hangzhou, Zhejiang, China (e-mail:lvtiangui@163.com, wucifang@zju.edu.cn). zone in developing areas. How to coordinate social-economic development with resources endowment?

In the past few years, many scholars had put forward some research on the relationship between resources and economic development. Some Scholars [3] analysis the coupling mechanism between urban economic development and the capacity of land resources. And the gene coefficient was employed to research on the relationship between carrying capacity of water resources and economic development in Yellow River Basin [4]. Further more, the coordination degree also has been used to analysis the relationship between the carrying capacity of water resources and economic development of Heilongjiang province and Bahai City Group in northern China [5]-[6]. In view of the above-mentioned literature, most results shows that the single index of land or water resources are employed to couple with the economic development by the means of the coordination degree. But the indicator of this index is obviously insufficient due to the natural link between land and water resources.

Therefore, in order to avoid the single index situation, in this paper, the index of carrying capacity of land and water resources are taken to analysis the relationship in the process of economic development, and combing with the protection strategy of "last pot of clear water "and urbanization development stage, the Poyang Lake Ecological Economic Zone was taken as an study area, which is in the central region of China. Through the information entropy method [7], the coupling degree is evaluated between economic development and land and water resources, which not only had overcome the shortcoming of single resource index theoretically, but also improve the resources allocation efficiency in practice, and provide references for the construction of other ecological economic zone.

\section{Procedure For PAPER SUBMISSION}

\section{A. Study Area}

Poyang Lake Ecological Economic Zone is Located in the north part of Jiangxi Province, and in the central of China, Poyang Lake is China's largest freshwater lake and also the central of Ecological Zone. The geographic coordinates of longitude $114^{\circ} 29^{\prime}-119^{\circ} 42^{\prime}$, north latitude $27^{\circ} 30^{\prime}-30^{\circ} 06^{\prime}$ (as shown in Fig.1) .Poyang Lake has unique geomorphologic features, and its water residence time is short. Poyang Lake is a kind of flushing lake with dramatic seasonal water level changes. The renewal period of lake water is particularly short (the period of water renewal is just 59 days). On the 
other hand, the matching of the Poyang Lake basin physical boundary with the provincial administrative boundary enables adaptive management of the entire Poyang Lake Ecological Economic Zone [1]. All these advantages make Poyang Lake not only has become the ecological barrier of lower reaches of Yangtze River in China, and an important wetland in Asia ,but also become an important ecological zone delineation of global was designated by the World-Wide Fund[8]- [9].

According to "The planning of Poyang Lake Ecological Economic Zone" which was approved by the State Council in $2009^{[10]}$, it means that the characteristic of planning had changed from regional development to the national strategy. This areas including 31 districts (countrieslurban), and cover $51,000 \mathrm{~km}^{2}$, accounting for $30.69 \%$ in Jiangxi province. The Poyang Lake ecological zone is an important agricultural production base, with the total GDP of 548 billion RMB in
2010, accounting for $57.97 \%$ in Jiangxi province. In the next few years, it is urgent to increase the land and water supply in Poyang Lake Ecological Economical Zone with the rapid development of accelerating industrialization and urbanization. At the same time, owing to the unique features of the geographical unit of Poyang Lake Ecological Economical Zone, the quality of land and water is influenced by the river upstream and closely related to the effect of human activities and flood disasters, which including engineering water shortage and seasonal water shortage [11].Therefore, with the contradiction are aggravated gradually between the limited carrying capacity of land and water resources and limitless economic development, how to evaluate and improve the coordination degree has become an inevitable challenge in the process of construction in Poyang lake Ecological Zone [12].
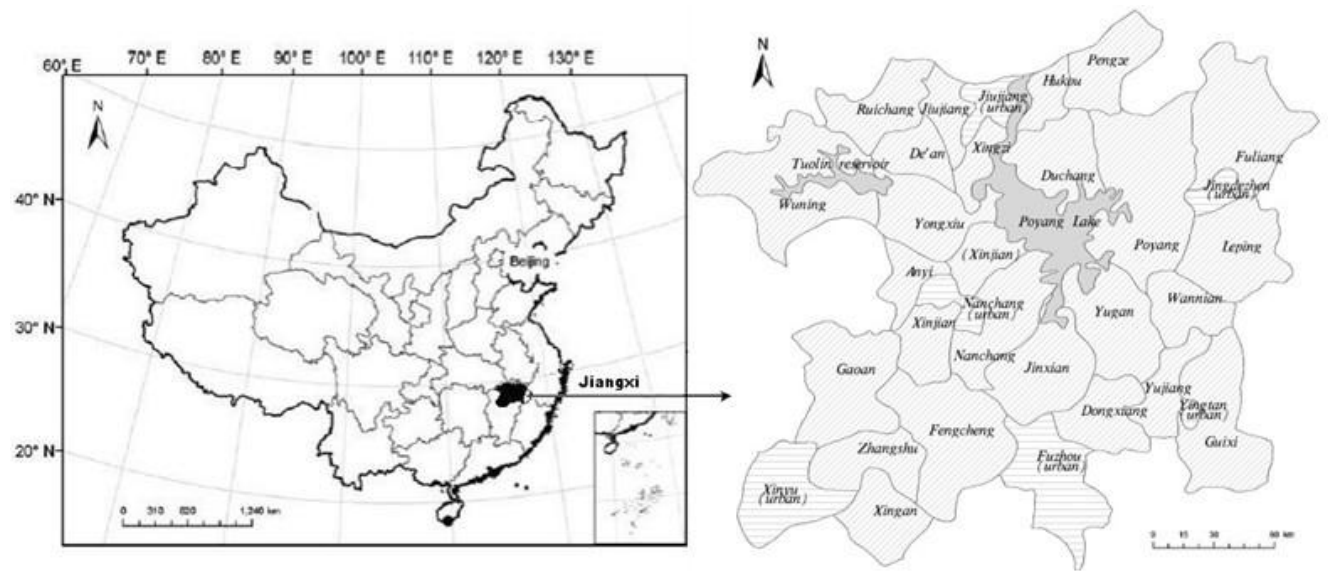

Fig. 1. Location of Poyang lake ecological economical zone in Jiangxi Province in China

\section{B. Research Methods}

The degree of coupling is described between the parameters in the process of system development synergy degree. According to the principle of coordination theory, the system from confusion to order lies in the synergistic system of internal subsystems, and the coupling degree is playing an important role in the synergy measurement [13]. The phase characteristics between the carrying capacity of land and water resources and economical development can be analyzed by the way of "coupling" method. In this study, the coupling degree is defined as the influence between the resources and economy through their respective elements interact each other and the data from statistical yearbook 2010 of Jiangxi province (Statistics Bureau of Jiangxi Province.2010). And the system which are consisted by the coupling model, the coupling coordination degree model and the coordinated development and criterion [14].

\section{1) Efficacy function}

In this study, no difference method of standardization is taken to standardization analysis in order to eliminate the difference because of units of each index. Owing to land and water resources index and economic index have a positive and negative, so the calculation formula as follows:

$$
\mu \mathrm{ij}=\left(\chi_{\mathrm{ij}}-\beta_{\mathrm{ij}}\right) /\left(\alpha_{\mathrm{ij}}-\beta_{\mathrm{ij}}\right), \mu_{\mathrm{ij}} \text { has positive effect }
$$$$
\mu \mathrm{ij}=\left(\alpha_{\mathrm{ij}}-\chi_{\mathrm{ij}}\right) /\left(\alpha_{\mathrm{ij}}-\beta_{\mathrm{ij}}\right), \mu_{\mathrm{ij}} \text { has negative effect }
$$

where variable $\mu_{\mathrm{i}}(\mathrm{i}=1,2, \mathrm{~L}, \mathrm{~m})$ as the order parameter, which $\mu_{\mathrm{ij}}$ representing the first $\mathrm{i}$ order and parameter $\mathrm{J}$ index, and the value means $\chi_{i j}(j=1,2, L, n)$; where $\alpha_{i j}$ and $\beta_{i j}$ are representing the minimal or maximal respectively in the stability critical point on the order parameter of the corresponding index system, while $\chi_{\mathrm{ij}}$ are on the efficacy coefficient system.

The entropy method has been taken to determine the weight of index, and the main calculation formulas are come from previous article ${ }^{[7]}$, and the weight of index in Poyang Lake Ecological Economic Zone can be obtained by related coupling formula. All these weight of index as final result (as shown in Table. I)

\section{2) Coupling degree function}

The coupling degree model of interaction between multiple systems are from the coupling coefficient of capacity coupling concept and capacity model in physics based on the foundation of efficacy function(as shown in Formula 2).

$$
\mathrm{C}=\mathrm{m}\left\{\left(\mu_{1} \cdot \mu_{2} \cdots \mu_{\mathrm{m}}\right) /\left(\mu_{1}+\mu 2+\cdot \cdot \mu_{\mathrm{m}}\right)^{\mathrm{n}}\right\}^{1 / \mathrm{m}}
$$

In the formula $(2)$, where $\mu(\mathrm{n}=1,2, \cdot \mathrm{m})$ represent the value of each subsystem, and $\mathrm{m}$ represent the number of subsystems, while $\mathrm{C}$ represent the coupling degree and $\mathrm{C} \in[0,1]$.In this study, with a total of two subsystems, which are land and water resources system and economy system 
respectively. Thus $\mathrm{m}=2$, and also means that it can be calculated through the formula (2), and the formula $\mathrm{C}$ just as follows: $\mathrm{C}=2\left\{\left(\mu_{1} * \mu 2\right) /\left(\mu_{1}+\mu 2\right)^{2}\right\}^{1 / 2}$. Where $\mu_{1}$ represent the comprehensive value of carrying capacity of land and water resources, and while $\mu_{2}$ represent the comprehensive value of economic development.

\section{3) Coupling coordination degree model}

In the comparative study, the results is easy to deviate from the actual conditions, if the situation just relying solely on coupling degree. Therefore, it is necessary to construct the coupling coordination degree function of land and water resources and economic development system so as to judge the degree of coupling interaction, the coordination degree(as shown in Formula 3):

$$
D=(C \times T)^{1 / 2}
$$

where $\mathrm{D}$ represent the coordination degree, and $\mathrm{C}$ represent the coupling degree, while $\mathrm{T}$ represent the coordination index between carrying capacity of water and land resources and economy development( Formula 4 ):

$$
T=a \mu_{1}+b \mu_{2}
$$

where $\mathrm{a}, \mathrm{b}$ represent the undetermined coefficient. In this study, the contribution of the resources system and economic system are equal. With regard to this situation, $a=0.5, b=0.5$. While $\mu_{1}$ and $\mu_{2}$ represent the comprehensive value of land and water resources and the comprehensive value of economic development respectively.

\section{Classification System and Criterion of Coordination}

According to the size of the extent of coordination degree, the system is divided into 4 categories and 10 subcategories, and then combine with the relationship between the comprehensive value of the carrying capacity of land and water resources $\left(\mu_{R}\right)$ and the comprehensive value of the economic development $\left(\mu_{\mathrm{E}}\right)$, which will be divided into different types (as shown in Table I).

\begin{tabular}{|c|c|c|c|}
\hline Coordination level & Range & Coupling coordination type & Comparison relationship between $\mu_{\mathrm{R}}$ and $\mu_{\mathrm{E}}$ \\
\hline \multirow{2}{*}{ Extreme coordination } & $0.91 \sim 1.00$ & Extreme coordination class & \multirow{5}{*}{$\begin{array}{c}\text { (1) } \mu_{R}>\mu_{\mathrm{E}} \text {, As the kind of economic lag: } \\
\mu_{\mathrm{E}} / \mu_{\mathrm{R}}>0.6 \text {,economic slightly lag, } \\
0.4<\mu_{\mathrm{E}} / \mu_{\mathrm{R}} \leq 0.6 \text {, economic moderate lag } \\
0<\mu_{\mathrm{E}} / \mu_{\mathrm{R}} \leq 0.4 \text {, economic obvious lag, } \\
\text { (2) } \mu_{\mathrm{R}}<\mu_{\mathrm{E}} \text {, As the kind of environmental damage: }\end{array}$} \\
\hline & $0.81 \sim 0.90$ & High coordinated class & \\
\hline \multirow{3}{*}{ High coordination } & $0.71 \sim 0.80$ & Good coordination class & \\
\hline & $0.61 \sim 0.70$ & Intermediate coordination class & \\
\hline & $0.51 \sim 0.60$ & Primary coordination class & \\
\hline \multirow{2}{*}{ Moderate coordination } & $0.41 \sim 0.50$ & Harmonic coordinate class & \multirow{5}{*}{$\begin{array}{c}0.4<\mu_{\mathrm{R}} / \mu_{\mathrm{E}} \leq 0.6 \text {, environment moderate damage, } \\
0<\mu_{\mathrm{R}} / \mu_{\mathrm{E}} \leq 0.4 \text {, environment obvious damage. } \\
\text { (3) } \mu_{\mathrm{R}}=\mu_{\mathrm{E}}, \text { as the economic environment of synchronous } \\
\text { type. }\end{array}$} \\
\hline & $0.31 \sim 0.40$ & Reluctant coordination class & \\
\hline \multirow{3}{*}{ Low coordination } & $0.21 \sim 0.30$ & Mild incoordination class & \\
\hline & $0.11 \sim 0.20$ & Moderate incompatible class & \\
\hline & $0.01 \sim 0.10$ & Incoordination class & \\
\hline
\end{tabular}

TABLE I: THE ClassificATION SYSTEM AND CRITERIA OF COUPLING ASSESSMENT BETWEEN RESOURCES AND ECONOMIC DEVELOPMENT

Note: where $\mu_{\mathrm{R}}$ represent the comprehensive value of the carrying capacity of land and water resources, while $\mu_{\mathrm{E}}$ represent the comprehensive value of the economic development.

\section{The Coupling Degree of Evaluation TABle System AND WEIGHT CALCULATION}

\section{A. The Coupling Degree Evaluation Index System}

In the process of the construction of coupling index system, which not only should reflect the relationship of land and water resources and economic development, but also need to consider the data available. According to the mentioned above principles, the framework of Pressure-State-Response was taken to evaluate the index of land and water resources, while the overall structure and efficiency was taken to reflect the indictors of the economic development(as shown in Table II).

\section{B. Calculation Method of Order Parameter Index Weight}

In this paper, the information entropy has been used to calculate the weight of each index, so as to avoid the subjective weight deviation, as shown in Table II.

\section{RESUlTS AND ANALYSIS}

The final results had been obtained by calculation, including the comprehensive evaluation index of land and water resources $\left(\mu_{R}\right)$ the comprehensive evaluation index of economic development $\left(\mu_{E}\right)$ coupling degreelcoordination degree and the contrast between $\mu_{R}$ and $\mu_{E}$ (as shown in Table III).

In the view of coordination degree, it obviously difference that the coupling degree between the land and water resources and economic development in Poyang Lake Ecological Economic Zone. In urban areas, the coupling overall level is lower, where the minimum in Fuzhou (urban) is 0.112 , and the maximum level is 0.621 in Nanchang (urban). In the countries areas, expect from the coupling degree of Nanchang County is greater than 0.9 , the rest of other countries is less than 0.7 , which means the lowest is 0.209 in Ruichang. From the spatial distribution (as shown in Fig. 2), the Coupling degree with Poyang Lake as the core and In circle form outwards gradually decreasing trend, and also shows that the distribution of carrying capacity of land and water resources inequality.

In the view of coordination degree, the extent of this belongs to moderate and low harmony generally other than the Nanchang (urban), Nanchang country and Fengcheng are in a highly coordinated. The coordination degree between the carrying capacity of land and water resources and economic development within Poyang Lake ecological economic zone 
is best for the city of Yichun, with an average value of 0.513 and belongs to high coordination, followed by the Nanchang city, the average value is 0.493 , and the coordination degree is moderate, the worst for the city of Fuzhou, with the average value is 0.234 , belong to low harmony. In the spatial distribution, coordination degree is still in Poyang Lake as the core, the overall layout of outward in a circle form progressively step by step.

TABLE II: INDEX SySTEM OF COUPLING ASSESSMENT BETWEEN RESOURCES AND ECONOMY

\begin{tabular}{|c|c|c|c|}
\hline System & Indicator & Index name & Weight \\
\hline \multirow{9}{*}{$\begin{array}{c}\text { The carrying capacity of } \\
\text { land and water resources } \\
\text { system }\end{array}$} & \multirow{3}{*}{$\begin{array}{c}\text { Pressure } \\
(0.341)\end{array}$} & Per capita arable land area $\left(\mathrm{hm}^{2}\right)$ & 0.105 \\
\hline & & Area of cultivated land at the end of the year $\left(\mathrm{hm}^{2}\right)$ & 0.170 \\
\hline & & Per capita water resources $\left(\mathrm{m}^{3}\right)$ & 0.066 \\
\hline & \multirow{3}{*}{$\begin{array}{l}\text { State } \\
(0.319)\end{array}$} & Water and soil resources proportion coefficient $\left(\mathrm{m}^{3} / \mathrm{hm}^{2}\right)$ & 0.043 \\
\hline & & Effective irrigation area $\left(\mathrm{hm}^{2}\right)$ & 0.170 \\
\hline & & Gross amount of water resources $\left(0.1\right.$ billion $\left.\mathrm{m}^{3}\right)$ & 0.106 \\
\hline & \multirow{3}{*}{ Response $(0.340)$} & The proportion of cultivated land resources $(\%)$ & 0.153 \\
\hline & & Farmland irrigation rate $(\%)$ & 0.097 \\
\hline & & Million Yuan of industrial water use two or three $\left(\mathrm{m}^{3} / 10\right.$ thousand $)$ & 0.090 \\
\hline \multirow{8}{*}{$\begin{array}{c}\text { Economic development } \\
\text { system }\end{array}$} & \multirow{3}{*}{$\begin{array}{l}\text { General } \\
(0.732)\end{array}$} & The per capita GDP(Million RMB) & 0.116 \\
\hline & & GDP(Billion RMB) & 0.289 \\
\hline & & The per unit area of land revenue(Billion RMB) & 0.326 \\
\hline & \multirow{2}{*}{$\begin{array}{l}\text { Structure } \\
(0.142)\end{array}$} & The proportion of the primary industry $(\%)$ & 0.078 \\
\hline & & The proportion of the tertiary industry $(\%)$ & 0.064 \\
\hline & \multirow{3}{*}{$\begin{array}{l}\text { Efficiency } \\
(0.126)\end{array}$} & The comprehensive index of industrial economic benefits (\%) & 0.020 \\
\hline & & The second industry increase rate $(\%)$ & 0.048 \\
\hline & & The tertiary industry increase rate $(\%)$ & 0.059 \\
\hline
\end{tabular}

Note: The sources of data come from Statistical Yearbook of Jiangxi Province, and the Bulletin of social economic development in 2010

3) From the types of coupling coordination degree, which are belongs to moderate uncoordinated and mild incompatible types within Poyang Lake Ecological Economic Zone. It obverted that the Nanchang is best city in the intermediate coordinated class. The County of Jiujiang, Yongxiu and De'an belongs to mild not conforming. Most of the moderate uncoordinated regional belongs to urban areas and showed that uneven distribution, such as urban of Jiujiang, Jingdezhen and Yingtan.

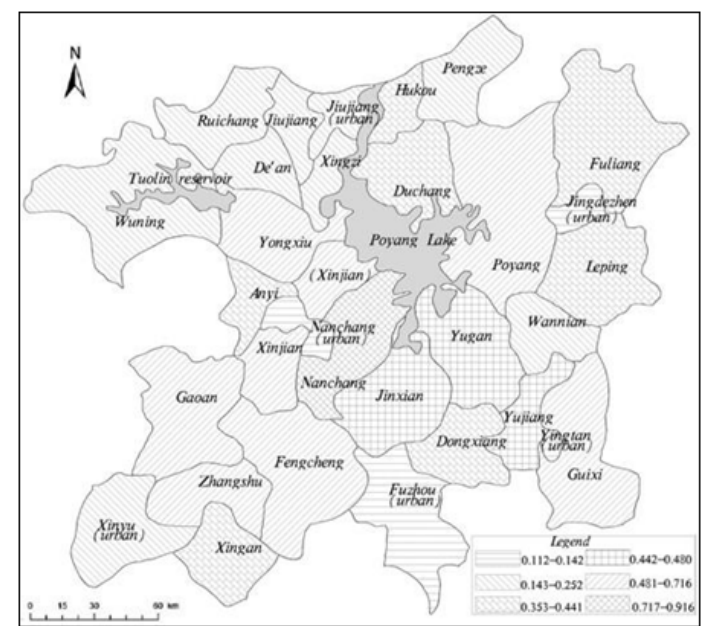

Fig. 2. The spatial distribution of coupling degree between resources and economy in Poyang Lake Ecological Economic Zone

4) From the comparison results of the $\mu_{R}$ and $\mu_{E}$ can be seen that there are six environmental lag areas and twenty-five economy lag areas, which belongs to urban and countries areas respectively. And the results also shows that the carrying capacity of land and water resources is not synchronized with the economic development of in Poyang Lake ecological economic zone. When $\mu_{R}<\mu_{E}$, this areas belongs environmental lag and also shows that the threshold of the carrying capacity of land and water resources less than the economic development. In view of these regions, more maintenance and improvement should be put into the carrying capacity of land and water resources in the process of construction. All these would be benefit to avoid paying much attention to economic development and ignore the law of inherent ecological carrying capacity. When $\mu_{R}>\mu_{E}$, it means that belongs to economic lag areas, and also shows that the development and utilization of land and water resources is lag behind the economic development. These regional resources should be development and utilization according to maximum threshold of land and water and based on the law of ecological environment.

\section{V.The optimal Path Selection BetweEn ResourCes AND ECONOMIC DEVELOPMENT}

When $\mu_{R}=\mu_{E}$, it means that the coupling degree of the optimal relations between the carrying capacity of land and water resources and economic development, belongs to the resource economy synchronous type. However, there is not a country or urban district among 31 countries of Poyang Lake Ecological Economic Zone in 2010 be in the " $\mu_{\mathrm{R}}=\mu_{\mathrm{E}}$ " model. All these situation illustrated that the coupling degree 
between resources and economy is still grim. Especially with the urbanization and industrialization is inseparable from the protection of land and water resources, while the excessive exploitation of water and soil resources will bring pressure on resources and environment in process of economic development. From comparison of type in table. 3 shows that environmental hysteresis region belongs to county, while the economic hysteresis region is mostly in urban. Therefore, the dual optimization path through the adoption of "Economic oriented" and "Resource guidance" respectively(as shown in Fig. 3), all those effective coupling measures between the carrying capacity of land and water resources and economic development would be benefit to realize the strategic target of ecological Protection and economic development in Poyang lake ecological economic zone.

TABLE III: THE RESUlTS OF COUPLING ASSESSMENT BETWEEN RESOURCES AND ECONOMY IN POYANG LAKE ECOLOGICAL ECONOMIC ZONE

\begin{tabular}{|c|c|c|c|c|c|c|c|}
\hline Administration division & $\mu_{\mathrm{R}}$ & $\mu_{\mathrm{E}}$ & Coupling degree & $\begin{array}{c}\text { Coordination } \\
\text { degree }\end{array}$ & $\begin{array}{c}\text { Coordination } \\
\text { level }\end{array}$ & $\begin{array}{c}\text { Coupling } \\
\text { coordination type }\end{array}$ & Comparison \\
\hline Nanchang (urban) & 0.129 & 0.825 & 0.621 & 0.544 & High & Primary class & EOD \\
\hline Nanchang & 0.783 & 0.251 & 0.916 & 0.688 & High & Intermediate class & EOL \\
\hline Xinjian & 0.655 & 0.195 & 0.607 & 0.508 & Moderate & Harmonic class & EOL \\
\hline Anyi & 0.461 & 0.130 & 0.289 & 0.292 & Low & Mild incoordination & EOL \\
\hline Jinxian & 0.625 & 0.152 & 0.480 & 0.432 & Moderate & Harmonic class & EOL \\
\hline Jiujiang(urban) & 0.116 & 0.345 & 0.184 & 0.206 & Low & Moderate incompatible & EOD \\
\hline Jiujiang & 0.384 & 0.131 & 0.232 & 0.244 & Low & Mild incoordination & EOL \\
\hline Yongxiu & 0.469 & 0.140 & 0.311 & 0.308 & Moderate & Mild incoordination & EOL \\
\hline De'an & 0.332 & 0.163 & 0.231 & 0.239 & Low & Mild incoordination & EOL \\
\hline Xingzi & 0.299 & 0.197 & 0.241 & 0.245 & Low & Mild incoordination & EOL \\
\hline Duchang & 0.486 & 0.131 & 0.311 & 0.310 & Moderate & Reluctant class & EOL \\
\hline Hukou & 0.394 & 0.166 & 0.286 & 0.283 & Low & Mild incoordination & EML \\
\hline Pengze & 0.428 & 0.122 & 0.251 & 0.263 & Low & Moderate incompatible & EOL \\
\hline Ruichang & 0.340 & 0.140 & 0.209 & 0.224 & Low & Mild incoordination & EML \\
\hline Wuning & 0.352 & 0.153 & 0.234 & 0.243 & Low & Mild incoordination & EOL \\
\hline Jingdezhen (urban) & 0.091 & 0.323 & 0.142 & 0.171 & Low & Moderate incompatible & EOD \\
\hline Leping & 0.378 & 0.166 & 0.272 & 0.272 & Low & Mild incoordination & EML \\
\hline Fuliang & 0.382 & 0.177 & 0.291 & 0.285 & Low & Mild incoordination & EML \\
\hline Yingtan (urban) & 0.109 & 0.240 & 0.113 & 0.14 & Low & Harmonic class & EMD \\
\hline Guixi & 0.550 & 0.241 & 0.575 & 0.477 & Moderate & Reluctant class & EML \\
\hline Yujiang & 0.503 & 0.193 & 0.434 & 0.389 & Moderate & Primary class & EOL \\
\hline Fengcheng & 0.693 & 0.221 & 0.716 & 0.572 & High & Harmonic class & EOL \\
\hline Zhangshu & 0.572 & 0.214 & 0.552 & 0.466 & Moderate & Harmonic class & EOL \\
\hline Gao'an & 0.670 & 0.180 & 0.589 & 0.500 & Moderate & Reluctant class & EOL \\
\hline Yugan & 0.571 & 0.155 & 0.433 & 0.397 & Moderate & Harmonic class & EOL \\
\hline Poyang & 0.750 & 0.138 & 0.570 & 0.503 & Moderate & Mild incoordination & EOL \\
\hline Wannian & 0.405 & 0.135 & 0.252 & 0.261 & Low & Moderate incompatible & EOL \\
\hline Fuzhou (urban) & 0.163 & 0.172 & 0.112 & 0.137 & Low & Reluctant class & ESD \\
\hline Dongxiang & 0.461 & 0.162 & 0.342 & 0.326 & Moderate & Mild incoordination & EOL \\
\hline Xinyu (urban) & 0.125 & 0.416 & 0.246 & 0.258 & Low & Mild incoordination & EOD \\
\hline Xingan & 0.438 & 0.155 & 0.309 & 0.303 & Low & Primary class & $\mathrm{EOL}$ \\
\hline
\end{tabular}

Note:(1) $\mu_{\mathrm{R}}=\mu$ resource, $\mu_{\mathrm{E}}=\mu$ economy.(2)ESL=economic slightly lag,EML=economic moderate lag,EOL= economic obvious lag,(3)ESD=environment slight damage,EMD=environment moderate damage, $\mathrm{EOD}=$ environment obvious damage.

\section{A. The Optimal Path Selection in Environmental Damaged Region}

1) Taking the adaptive management mode so as to meet the changing needs of the ecological environment. The dynamic changes and uncertainty of land and water resources are the constraints of resources management, while the adaptive management mode is and effective method to deal with this complexity problems effectively. The construction of adaptive management needs to establish measurable goals based on the two aspects of the ecological system's functions and social development, and then through scientific management monitoring and controlling so as to improve data collection level in order to meet the changes in demand of ecological system capacity and social requirement[16]. According to the environmental lag areas, it is necessary to combined with the ecological threshold of land and water 
resources and the variation in demand of economic development, and then take the carrying capacity of land and water resources as the core to control the strategy of supply and demand. Therefore, these would be benefit to improve the coupling coordination degree between carrying capacity of land and water resources and economic development.

2) Providing the better environment of land and water resources through the construction of ecological barrier. As to the construction of ecological barrier is not only the inherent requirements of "a lake of water "protection in Poyang Lake, but also the whole characteristic objective demand of " lake-watershed "maintenance in Poyang basin ${ }^{[17]}$. Especially the Poyang lake ecological economic zone as the center of the material energy in the lower reaches, these regions need more fresh air, land and water resources in the process of economic development. But the effects of these sources is not only depends on the ecological environment itself within the Poyang lake ecological economic zone, but more depends on the whole basin of Poyang lake, and also related to a series of natural processes and human activities. Therefore, the improvement of carrying capacity of land and water resources has become the key to the construction of ecological barrier. There are several ways to promote the construction of ecological barrier. Firstly, strengthening the research on the inherent law of ecological system. Secondly, Construction of the subject's initiative as the core of ecological compensation mechanism in order to improve the ecological barrier areas, including the implementation of the financial transfer payment, preferential policies, industry support and technical personnel training and so on.

\section{B. The Optimal Path Selection in Economical Lag Region}

1) Improving the basic guarantee ability of economic construction through the optimization of urban land resources allocation. From the Table III shows that most of areas are belongs to the economical lagging behind region, also means that the land and water resources utilization is far below the threshold of resource capacity. The land resources optimization allocation is the best way to promote the urbanization $^{[18]}$,including the structure of land use optimization, time and land use spatial layout optimization, land use efficiency optimization. Therefore, by optimizing the allocation of land resources, which will effectively protect needs of the economy lag urbanization infrastructure, so as to promote the economic construction in Poyang lake Ecological Economic Zone

2) Speeding up the upgrading of regional industrial optimization so as to improve the coordination degree between resource and economic coordination. Strengthening the economic hysteresis region industry upgrade and optimization is the core to improve the level of coordination of resources and economy. It should be according to the distribution of land and water resources to develop the industries with local characteristics in Poyang lake ecological economic zone. In the lakeside range, the basic measures including the upgrading the agricultural industry, promoting the ecological tourism and developing the green industries in main. While in the lake peripheral region through optimizing agricultural industry, constructing the ecological industrial park and developing the ecological tourism service industry. And through different industries upgrade optimization and combination would bring the industrialization and urbanization within Poyang lake ecological economy zone, what would be benefit to promote the comprehensive development of regional social economy under the premise of resources and the environment's protection.

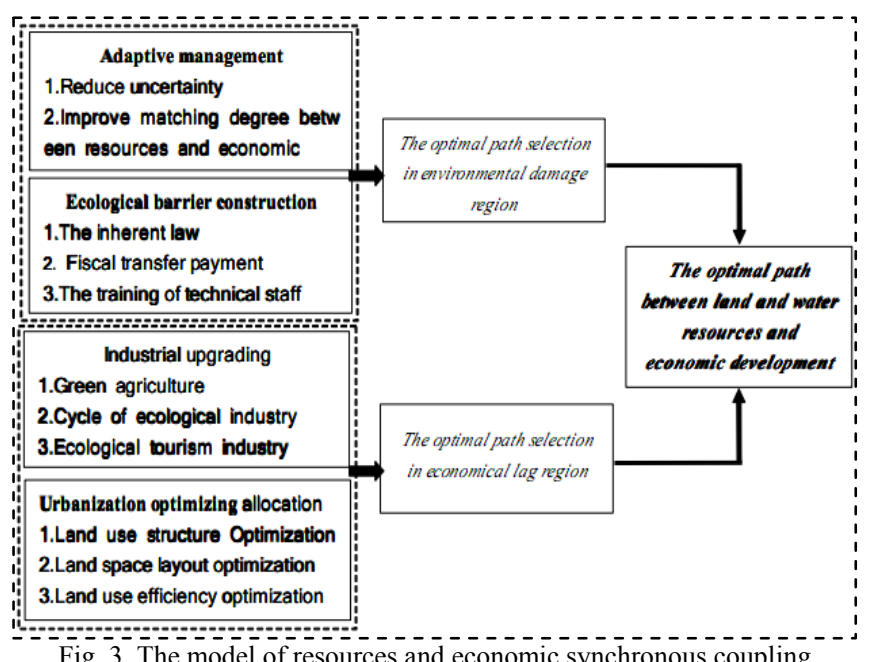

Fig. 3. The model of resources and economic synchronous coupling optimization in Poyang Lake Ecological Economic Zone

\section{CONCLUSION}

It was obvious that the distribution of the coupling degree between land and water resources and economic development was different from 0.112 to 0.996 in 31 countries in 2010 in Poyang lake ecological economic zone. While the coordination degree was obvious different, the distribution of the value was from 0.137 to 0.688 , and this situation illustrated that the majority of regions were in low intensity coupling and differentiation stage. The conclusions as follows:

1) It was obvious that the characteristic of coupling coordination was unbalanced. The level of the coupling degree and coordination degree was lower, all these formats present in the circle also had the trend of decreasing outward.

2) The urban areas belonged to the moderate incompatible types and environment lagging region, while the country (district) was mild not coordinated and belonged to economic lagging region. And the Nanchang country was best area that had the highest coordination degree of coupling with the intermediate coordination type.

3) The Simultaneous optimization of resources and economy was the best way to improve the coupling degree and promote regional development in balance. Mainly urban environment hysteresis region should choose the adaptive management and ecological barrier construction strategy, and the county oriented economy lag area should choose the urbanization and industrialization development strategy.

4) Owing to the existence of uncertainty and complexity from the intertwined between land and water, as well as the economic development was influenced by the local natural resources and social and cultural practices, so that the coupling evaluation index selection becomes more complex. Therefore, How to select a more rational and adaptive index 
and quantify the coupling degree has become a main direction of future research in the field of land and water resources.

\section{REFERENCES}

[1] M. Q .Chen, X. H. Wei, H. S. Huang, and T. G. Lv, "Poyang Lake basin: a successful, large-scale integrated basin management model for developing countries," Water Science \& Technology, vol. 26, pp. 1899-1905, Oct. 2011.

[2] S. D. Ren, Q. Fu, and K. Wang, "Research progresses of regional water and soil resources carrying capacity," System Sciences and Comprehensive Studies in Agriculture, vol. 26, pp. 222-226, May 2010. (In Chinese).

[3] J .T .Wu, J. J. Tu, X. Yan, and Y. Zhou, "Study on the coupling mechanism between urban land use benefits and urbanization in China" Urban Studies, vol. 18, pp. 42-45, Oct. 2011. (In Chinese).

[4] X. T. Zhang and F. W. Yu, "Analysis of the matching status between economic development and water resources in the Yellow River basin," China Population, Resources and Environment, vol. 22, no. 10, pp. 1-6, Oct. 2012.(In Chinese).

[5] D. Y. Li and S. W. Zhang, "Evaluation on coordination degree between water resources and social economic development in Heilongjiang Province," Journal of Arid Land Resources and Environment, vol. 24, no. 4, pp. 8-11, Apr. 2010. (In Chinese).

[6] D. R. Wang, S. Q. Zhao, and X. S. Li, "Discussion on the dynamic assessment of the carrying capacity of water resources in west Bohai rim upon economic development," China soft Science Magazine, vol. 6 , pp. 86-93, Jun. 2009. (In Chinese).

[7] L. Zhao, H. L. Liu, and G. F. Yu, "A case study on HuLuDao city: comprehensive evaluation of sustainable utilization of land resources via entropy method," Resources \& Industries, vol. 14, no. 4, pp. 63-68, Aug. 2012. (In Chinese).

[8] Q. G. Zhao, G. Q. Huang, and H. Y. Qian, "Ecological environment and sustainable development of Poyang lake," Acta Pedologica Sinica, vol. 44, no. 2, pp. 318-326, Mar. 2007. (In Chinese)

[9] Y. Wang."The inspection review of make good use of the basin of water--Poyang Lake water resources protection and exploitation," Journal of CPPCC, vol. 12, pp. 32-35, Dec. 2006. (In Chinese).

[10] The State Council. (December 2009). The planning of Poyang Lake Ecological Economic Zone. The Xinhua News Agency. [Online] Available: http://www.gov.cn/jrzg/2009-12/16/content_1488908.htm

[11] The Xinhua News Agency. (August 2012). China's largest freshwater lake faces water shortage. The Xinhua News Agency. [Online]. Available:http://www.jx.xinhuanet.com/news/fmbd/2012-08/26/c_11 2851037.htm
[12] The State Council. (December 2009).The central economic work conference in 2012. The People News Agency. [Online]. Available: $\mathrm{http} / / /$ finance.people.com.cn/GB/jinji/222/2322/.

[13] D. L. Wu, L. Cao, and L. H. Chen, "Principle and application of synergetic," WH: Huazhong University of science and Technology Press, ch.1, pp. 9-17, 1990. (In Chinese)

[14] Statistics Bureau of Jiangxi Province, Jiangxi Statistical Yearbook, BJ: China Planning Press, 2010.(In Chinese)

[15] Z. Y. Ren, Q. Xu, and R. Yang. "On coordination development of agricultural ecological-environment and economy in Shan-xi Province based on coupling degree model," Journal of Arid Land Resources and Environment, vol. 25, no. 12, pp. 14-19, Dec. 2011. (In Chinese).

[16] K. A. Vogt, J. C. Gordon, J. P. Wargo, et al., "Ecosystems: Balancing science with management," New York: Springer, 1997.

[17] M. Q. Chen, T. J. Liu, and T. G. Lv, "Research on construction of ecological barrier for ecological and economical zone of Poyang lake," Yangtze River, vol. 42, no. 11, pp. 64-67, June 2011. (In Chinese).

[18] M. Q. Chen. "Study on land allocation in the process of urbanization in China," BJ: Xinhua press, ch.4, pp.114-117, 2004.

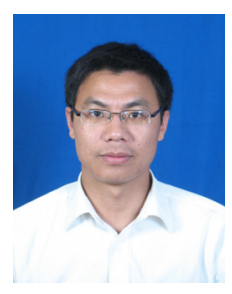

Tian-gui Lv was born in the city of Longyan in Fujian Province in 1986, and now he is a Ph.D Candidate in Zhejiang University, and majors in land use planning and ecological protection. In recent years, he studies on the coupling mechanism of land and water resources carrying capacity in Poyang Lake. And some research findings had been published in the local magazine. For example, the title of paper "Thinking on mechanism of eco-compensation in the Poyang Lake Basin "had been published in the journal of China Engineering Science,Vol.12, No.6, pp.85-89, Dec 2010. (In Chinese), and paper the title of "Poyang Lake basin: a successful, large-scale integrated basin management model for developing countries "had been published in the journal of Water Science \& Technology, Vol. 26, pp. 1899-1905, Oct 2011. (SCI).

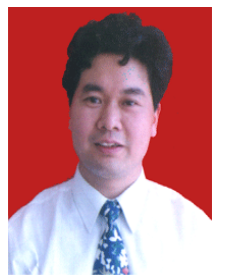

Ci-fang Wu was born in the city of Tai Shun in Zhejiang Province in 1954, and now he is with a $\mathrm{PhD}$, Professor, Doctoral tutor of the College of Public administration in Zhejiang University, and majors in land use planning. And Prof. Wu is a famous expert in the field of land use planning and land consolidation in China. 